\title{
Smoking and diseases of the gastrointestinal system: An epidemiological review with special reference to sex differences
}

\author{
Mary Jane Ashley MD DPH MSc FRCPC
}

MJ Ashley. Smoking and diseases of the gastrointestinal system: An epidemiological review with special reference to sex differences. Can J Gastroenterol 1997;11(4):345-352. Smoking increases the risk of peptic ulcer disease and death from it. Smoking delays peptic ulcer healing, with or without treatment, and increases the risk of recurrence after healing. The effects of smoking on this disease are similar and equally pervasive in women and men. There is growing evidence that cigarette smoking is a risk factor for Crohn's disease (CD) in both women and men. However, women smokers appear to be at particular risk for this disease. In studies that examined this risk separately in women and men, at each level of smoking the excess risk in women smokers compared with nonsmokers clearly exceeded the excess risk in men smokers compared with nonsmokers. Smoking also appears to adversely affect the clinical course of CD in both women and men, but more so in women. The possible interaction between smoking and oral contraceptives with regard to the risk of CD deserves further study. There is growing evidence that current smoking protects against ulcerative colitis in both men and women. Although there is some evidence that smoking is a risk factor for gallstones, particularly in women, evidence to support a causal relationship is inadequate. Further studies, controlling for alcohol consumption in the analyses, are needed. Smoking does not appear to be a risk factor for cirrhosis of the liver.

Key Words: Gastrointestinal diseases, Sex, Smoking

\section{Tabagisme et maladies de l'appareil digestif : épidémiologie et différences sexuelles}

RÉSUMÉ : Le tabagisme accroît le risque d'ulcère gastro-duodénal et la mortalité qui y est associée. Il retarde la cicatrisation avec ou sans traitement et augmente le risque de récurrence de l'ulcère gastro-duodénal après la guérison. Les effets du tabagisme sur cette maladie sont semblables et aussi répandus chez les femmes que chez les hommes. Les preuves s'accumulent à l'effet que la cigarette est un facteur de risque de maladie de Crohn tant chez l'homme que chez la femme. Toutefois, les fumeuses semblent exposées à un risque particulier à l'égard de cette maladie. Dans le cadre d'études qui se sont penchées sur le risque lié au sexe, à chaque degré de tabagisme, le risque observé chez les fumeuses excédait clairement le risque observé chez les fumeurs en comparaison avec les non-fumeurs. Le tabagisme semble également influer négativement sur l'évolution clinique de la maladie de Crohn chez la femme et chez l'homme, mais davantage chez la femme. L'interaction possible entre tabagisme et contraceptifs oraux pour ce qui est du risque de maladie de Crohn mérite qu'on s'y attarde davantage. Les preuves s'accumulent à l'effet que le tabagisme protège contre la colite ulcéreuse chez l'homme et la femme, bien que selon certaines conclusions, il soit un facteur de risque de calculs biliaires, particulièrement chez la femme, mais les preuves d'un tel lien causal sont inadéquates. Il faudra procéder à d'autres études pour vérifier le rôle de la consommation d'alcool dans ces analyses. Le tabagisme ne semble pas poser de risque à l'égard de la cirrhose du foie.

Department of Preventive Medicine and Biostatistics, and the Ontario Tobacco Research Unit, Centre for Health Promotion, University of Toronto, Toronto, Ontario

Correspondence: Dr Mary Jane Ashley, Department of Preventive Medicine and Biostatistics, Faculty of Medicine, University of Toronto,

Toronto, Ontario M5S 1A8. Telephone 416-978-2751, fax 416-978-8299, email ashley@pmb.med.utoronto.ca

Received for publication June 18, 1996. Accepted October 11, 1996 
$\mathrm{T}$ here is growing evidence concerning the effects of smoking on the gastrointestinal system. This review considers the link between smoking and peptic ulcer disease, Crohn's disease (CD), ulcerative colitis (UC), gallbladder disease (gallstones) and cirrhosis of the liver, primarily from an epidemiological viewpoint. The effects of smoking on $\mathrm{CD}$ may be more marked in women than in men. Also, it is well established that women have a propensity for gallbladder disease (1), and some subgroups of women in the population are thought to be predisposed to CD and UC (2). Therefore, in this review, particular attention is paid to sex differences in effects of smoking.

\section{PEPTIC ULCER DISEASE}

Large prospective epidemiological studies have documented the increased risk of death from peptic ulcer in male smokers compared with nonsmokers $(3,4)$. This risk was confirmed in a recent analysis of data from a study by Doll et al (5). This 40-year follow-up of male British doctors reported significantly more deaths from peptic ulcer in current smokers than in nonsmokers and a strong dose-response relationship. Large epidemiological and clinical studies provide additional evidence of a significant association between current smoking and peptic ulcer disease (6-12).

Although studies of women have been fewer in number and more limited in design (13), and mortality rates from peptic ulcer have been much lower in women than in men, at least until recently $(8,14,15)$, there is now substantial evidence that the effects of smoking on peptic ulcer disease in women are similar to those in men. Anda et al (13) used data from a large prospective study in the United States (the First National Health and Nutrition Examination Survey Epidemiologic Follow-up Study) to show that, during the 12.5 years of follow-up, the estimated cumulative incidence of peptic ulcers was $10 \%$ in women who were smokers at baseline, $6.4 \%$ in former smokers and $5.4 \%$ in women who never smoked. After adjusting for age, education, regular acetylsalicylic acid use, coffee consumption and alcohol use, current women smokers at baseline had 1.8 times the incidence of peptic ulcer disease (95\% CI 1.2 to 2.6) compared with women who had never smoked.

Using these data, Anda et al (13) estimated that about $20 \%$ of the incident cases of peptic ulcer disease in American women were attributable to smoking. In an earlier study, Kurata et al (16) reported that an estimated 25\% to $50 \%$ of duodenal ulcer mortality in women in the United States may be attributable to smoking. The corresponding figures for men were $43 \%$ to $63 \%$. English et al (17) used a pooled estimate of relative risk derived from several studies to estimate that $33 \%$ and $41 \%$ of peptic ulcer disease in Australian women and men, respectively, was caused by cigarette smoking.

The authors of a study of peptic ulcers in women enrolled in the Oxford Family Planning Association Study demonstrated a dose-response relationship between smoking and the risks of both gastric and duodenal ulcers (18). In a study of a randomly selected sample of the adult population of Gothenburg, Sweden, Schöön et al (19) showed that the risk of peptic ulcer was significantly higher among smokers in all age groups of both sexes than among corresponding nonsmokers. Among nonsmokers the incidence was greater in men than in women. However, there was no difference in risk between sexes among smokers. The authors of this study estimated that $24.5 \%$ and $26.5 \%$ of ulcers diagnosed for the first time in men and women, respectively, were attributable to smoking, as were $42.3 \%$ and $47.1 \%$ of recurrent ulcers. In this study (19), the risk of peptic ulcer was related to ever having smoked and not to duration of smoking, which is consistent with other evidence that much of the effect of smoking is immediate $(17,20)$.

The authors of several studies have demonstrated doseresponse relationships between amount of current smoking and risk of peptic ulcer disease $(5,13,18,21)$. However, Kato et al (9) analyzed pack-years of smoking, combining past and current smokers, and found a clear dose-response relationship between pack-years and age-adjusted risk of both gastric and duodenal ulcer.

Numerous ulcer therapy trials suggest that smoking adversely affects duodenal ulcer healing, and a meta-analysis showed the effect of smoking in both treatment and placebo groups (4). In the meta-analysis it was found that the median difference in percentage of subjects completely healed was 22 percentage points in favour of nonsmokers in groups treated with $\mathrm{H}_{2}$ blockers, 21.5 percentage points in favour of nonsmokers in groups receiving other active treatment and 22 percentage points in favour of nonsmokers in groups receiving placebo. A recent study further confirmed the adverse effect of smoking on duodenal ulcer healing (6). Evidence of an effect of smoking on the healing of gastric ulcer is not as substantial nor as clear cut (4). Some studies suggest a benefit of quitting smoking on gastric ulcer healing, but a number of clinical therapy trials do not provide evidence that outcomes differ between smokers and nonsmokers.

Prospective maintenance therapy trials have shown the adverse effect of smoking on duodenal ulcer recurrence. It has been shown repeatedly that smokers have more recurrences than nonsmokers, regardless of treatment, and several studies have shown that amount smoked is directly related to risk of recurrence $(4,22)$. In a twelve-month follow-up of patients with healed ulcers, Chang et al (6) found significant differences in relapses between smokers and nonsmokers, with smokers much less likely to be in remission at one, three, six and 12 months. Di Mario et al (23) studied duodenal ulcers in patients followed for up to 48 months and found that smokers had significantly more relapses, but fewer episodes of bleeding, than former smokers and never smokers. Multivariate analysis confirmed that smoking protects against bleeding. It was suggested that smoking might adversely influence recurrence through its effect on the epithelial surface, while it might 'protect' against bleeding through its effect on submucosal bloodflow. The adverse effect of smoking on the recurrence of gastric ulcers has also been shown in many studies (4).

Numerous mechanisms have been proposed to explain how smoking may adversely affect gastroduodenal physiol- 
TABLE 1

Pooled estimates of relative risks (RR) and $95 \% \mathrm{Cl}$ by cigarettes smoked per day in current smokers of all ages: Selected diseases of the gastrointestinal system

\begin{tabular}{|c|c|c|c|c|}
\hline \multirow{3}{*}{$\begin{array}{l}\text { Disease (number of studies } \\
\text { meeting inclusion criteria) }\end{array}$} & \multirow[b]{3}{*}{ Sex } & \multicolumn{3}{|c|}{ Cigarettes per day } \\
\hline & & $1-14$ & $15-25$ & $25+$ \\
\hline & & RR (95\% Cl) & RR $(95 \% \mathrm{Cl})$ & RR $(95 \%$ Cl) \\
\hline \multicolumn{5}{|l|}{ Sufficient evidence of causality* } \\
\hline Peptic ulcer (5) & Male and female & $1.69(1.60-1.78)$ & $2.38(2.26-2.50)$ & $1.90(1.52-2.37)$ \\
\hline \multicolumn{5}{|l|}{ Limited evidence of causality ${ }^{\dagger}$} \\
\hline \multirow[t]{2}{*}{ Crohn's disease $(7)$} & Male & $1.48(0.83-2.65)$ & $6.40(2.33-17.6)$ & $2.57(1.08-6.10)$ \\
\hline & Female $§$ & $4.40(2.60-7.45)$ & $9.40(3.43-25.8)$ & $3.03(1.02-8.95)$ \\
\hline Ulcerative colitis (9) & Male and female & $0.83(0.58-1.19)$ & $0.46(0.31-0.68)$ & $0.10(0.02-0.44)$ \\
\hline \multicolumn{5}{|c|}{ Inadequate evidence of causality $\ddagger$} \\
\hline Cholelithiasis (4) & Male and female & $1.14(1.01-1.28)$ & $1.18(1.06-1.30)$ & $1.38(1.25-1.52)$ \\
\hline
\end{tabular}

Adapted from reference 17. *Evidence of a causal association was considered to be 'sufficient' when chance, confounding and other bias could be ruled out with reasonable confidence, using well established criteria such as statistical significance and power, time order, strength of association, specificity of effect and/or cause, consistency on replication, predictive performance, theoretical coherence, biological coherence, factual coherence and statistical coherence; ${ }^{\dagger}$ If an association was observed for which a causal interpretation was credible, but chance, confounding or other bias could not be ruled out with reasonable confidence, the evidence was considered to be 'limited'; ${ }^{\prime}$ If the available studies were not of sufficient quality, consistency or statistical power to permit a conclusion regarding causality, the evidence was considered to be 'inadequate'; '\$ Within each smoking category relative risks were higher in women than in men

ogy leading to peptic ulcer disease $(4,20)$. Some of these effects are rapidly reversible with smoking cessation, which has been shown to affect favourably the course of peptic ulcer disease (4). For example, Scott et al (24) showed that acute cigarette smoking adversely affects intragastric distribution of solids and liquids and delays gastric emptying. Johnson et al (25) also demonstrated that smoking slows gastric emptying. McDonnell and Owyang (26) found that smoking caused a marked decline in gastric activity and elimination of all gastric phase III activity in both smokers and nonsmokers while smoking. Smoking also has been shown to increase gastric secretions (6), particularly in men $(27,28)$. Smoking may also depress prostaglandin synthesis in the gastric mucosa (29) and decrease mucosal bloodflow (20). An inhibitory effect of tobacco smoke on injuryinduced gastric mucosal hyperemia has also been shown experimentally (30). Although the evidence is neither conclusive nor without contradiction, in general, nicotine appears to act by potentiating the adverse effects of gastric aggressive factors such as acid and pepsin secretion, motility, duodenogastric reflux, the risk of Helicobacter pylori infection, levels of free radicals, vasopressin secretion, platelet-activating factor generation and endothelin generation. At the same time, nicotine attenuates defensive mechanisms by decreasing mucosal bloodflow, prostaglandin synthesis, mucus secretion and epidermal growth factor secretion (20).

Since the early 1980s, the role of $H$ pylori infection in peptic ulcer disease has been recognized and to some extent clarified (31-35). Bateson (36) found that $\mathrm{H}$ pylori infection and current smoking were strongly associated, and it has been hypothesized that cigarette smoking increases susceptibility to infection with these microorganisms, which, in turn, is strongly associated with both duodenal and gastric ulcer $(20,36)$. However, Chang et al (6) found no difference in $H$ pylori infection rates between smokers and nonsmokers. Further, a logistic regression model concerning the relative risks of age, sex, nationality, smoking and $H$ pylori infection in duodenal and gastric ulcer recently demonstrated that both cigarette smoking and $\mathrm{H}$ pylori infection were independently related to the risk of both duodenal and gastric ulcer, and smoking was a risk factor for unspecific pathological changes in the gastric mucosa (7).

In Canada, rates of mortality, hospitalization and surgical procedures for peptic ulcer disease declined significantly in men between 1950 and 1981 but changed little in women, among whom rates were already much lower in 1950 (14). This dramatic trend in peptic ulcer disease in men was associated with a parallel and marked decline in smoking among men during the same period, from 55\% to 39\% between 1965 and 1979, while the proportion of women who smoked remained constant, 31\% in 1965 and 30\% in 1979.

Thus, there is ample evidence from many sources that smoking has a pervasive adverse effect on peptic ulcer disease that is manifested similarly in women and men. Smoking increases the risk of occurrence of peptic ulcer, delays healing, with or without treatment, and increases the risk of recurrence after healing. This was recently confirmed by a review of the literature and a meta-analysis of five studies meeting specific criteria, conducted by English et al (17), as a basis for quantifying the costs of drug use in Australia. As shown in Table 1, smoking at all levels was found to increase the risk of peptic ulcer frequency, with the increase in risk being less with lower than with higher levels of smoking. There was little evidence that effects in men and women were different. These authors concluded that the relationship between smoking and peptic ulcer is causal.

\section{CROHN'S DISEASE}

An increased risk of $C D$ in association with smoking has been found in many studies. In a review of the literature published in the mid-1980s, Calkins and Mendeloff (2) noted several studies in which current smoking appeared to be a 
risk factor for CD. By the late 1980s, Calkins (37) identified seven studies that met the criteria for inclusion in a metaanalysis. She noted the remarkable consistency in the findings with regard to an association between smoking and CD, a consistency also found in several other studies that were reviewed and summarized by her that did not meet inclusion criteria. The meta-analysis yielded a pooled odds ratio of 2.0 (95\% CI 1.65 to 2.47). An increased risk was also found among former smokers, with a pooled odds ratio of 1.80 (95\% CI 1.33 to 2.51). In this meta-analysis a dose-response relationship between amount smoked and CD was not clear; however, direct risk relationships with both amount smoked and duration of smoking were made evident by an analysis that controlled for age, sex, marital status, education and body mass index (38).

The authors of three studies included in this metaanalysis reported risks for men and women separately. In each instance, the odds ratios in women exceeded those in men. The recent meta-analysis by English et al (17), summarized in Table 1, further supports the evidence that the relative risks of $\mathrm{CD}$ are elevated in both women and men who smoke, but more so in women. For each current smoking category the relative risks in women were greater than those in men. For any smoking, the pooled relative risk estimate was 3.27 (95\% CI 2.59 to 4.13 ) in women and 1.92 (95\% CI 1.24 to 2.96) in men. English et al (17) pointed out that the association of smoking with CD has been repeatedly demonstrated and was strong in every study they reviewed except one.

Recently, more studies have been done. Silverstein et al (39) demonstrated that patients with CD were more likely to smoke at the time of onset of symptoms than were control patients with irritable bowel syndrome. The age- and sexadjusted odds ratio was 3.71 (95\% CI 1.93 to 7.13). Persson et al (40) carried out a case-control study in Sweden and showed that the risk of $\mathrm{CD}$ in current smokers compared with never smokers was 4.99 (95\% CI 2.7,9.2) in women and $1.33(95 \%$ CI $0.7,2.6)$ in men. These investigators also found an elevated risk of $\mathrm{CD}$ in adults exposed to environmental tobacco smoke in childhood. The overall odds ratio was 1.50 (95\% CI 1.0 to 2.3). In women, it was 1.59 (95\% CI 0.8 to 3.0 ) and in men it was 1.37 (95\% CI 0.7 to 2.6). Tragnone et al (41) conducted an incidence study in Bologna, Italy and found a higher relative risk for CD in female smokers compared with female nonsmokers than in male smokers compared with male nonsmokers. Overall, the peak incidence of CD was among 20- to 29-year-olds, and among women with $\mathrm{CD}$ in this age group, $86 \%$ were smoking at the onset of the disease, yielding a relative risk of women smokers to nonsmokers of 11.6 (95\% CI 0.7 to $62.8, \mathrm{P}<0.05)$.

It has been postulated that oral contraceptive use may act independently to increase the risk of $\mathrm{CD}$ and/or that oral contraceptives might interact with smoking to increase the risk of CD in women. Vessey et al (42) analysed prospective data from the Oxford Family Planning Association study and examined the effects of smoking and oral contraceptive use on CD. Both factors were positively associated with CD.
However, the risk relationship of smoking with $\mathrm{CD}$ was changed little when oral contraceptive use was taken into account.

In a case-control study Sandler et al (43) found an interaction between smoking and oral contraceptive use. The risk of $\mathrm{CD}$ associated with oral contraceptive use was significantly elevated in current smokers (odds ratio 2.64, 95\% CI 1.22 to 5.75 ) but not in former smokers or never smokers. They also found that women who smoked appeared to be at increased risk of CD whether they used oral contraceptives or not, but the risk was significantly elevated only in users. For oral contraceptive users who smoked, the odds ratio was 3.18 (95\% CI 1.49 to 6.81$)$ and for nonusers who smoked it was 1.62 (95\% CI 0.73 to 3.62 ). These authors suggested that the interaction between oral contraceptive use and smoking may be a consequence of the thrombogenic effects of exposure to both, which has been postulated by others (44). Katschinski et al (45), however, did not find that oral contraceptive use increased the risk of CD in smokers. Increased risk with oral contraceptive use was found only in nonsmokers. In contrast, when oral contraceptive use was controlled, smoking was a clear risk factor for CD (odds ratio $3.0,95 \%$ CI 1.3 to 6.8 ). While the independent role of oral contraceptives in CD remains controversial, and the possible interaction of smoking and oral contraceptive use deserves further study, it seems clear that smoking increases the risk of $\mathrm{CD}$ in women, irrespective of oral contraceptive use.

Several studies also document a role of smoking in the clinical relapse of patients with CD. In a follow-up of 74 adult patients over six months, Duffy et al (46) found that current smoking, but not former smoking, was associated with an increased risk of clinical relapse. Current smokers had 1.6 times the risk of relapse of nonsmokers $(\mathrm{P}<0.01)$. Adjustment by linear regression for age, sex, duration of disease, surgical intervention and other potential confounding factors did not alter this finding. The two-way interactive effects of smoking with age, sex and duration of disease were considered, but none was statistically significant. Sutherland et al (47) also found that smokers were much more likely than nonsmokers to relapse because they required repeat surgery. After follow-up of 174 patients for five years, the relapse rate was $36 \%$ in smokers and $20 \%$ in nonsmokers, while after 10 years of follow-up the corresponding relapse rates were $70 \%$ and $56 \%$, respectively. However, in this study, the increased risk of relapse in relation to smoking was much more pronounced in women (odds ratio $4.2,95 \% \mathrm{CI}$ 2.0 to 4.2 ) than it was in men (odds ratio $1.5,95 \%$ CI 0.8 to 6.0), and evidence of a dose-response relationship was found in women. The five- and 10-year cumulative recurrence rates in women smokers were $40 \%$ and $76 \%$, respectively, compared with corresponding rates of $20 \%$ and $58 \%$ in women who were nonsmokers $(\mathrm{P}=0.002)$. Differences in recurrence rates at five- and 10-years' follow-up between women who smoked and women who did not were 23\% (95\% CI 5.3 to 39.5 ) and 39\% (95\% CI 20 to 58), respectively. Lindberg et al (48) found that smokers with CD, particularly heavy smokers, have increased risks of operation and reoperation 
compared with never smokers. Recently, Cosnes et al (49) showed that smoking adversely affects the clinical course of CD. Smokers required more glucocorticoids and immunosuppressive drugs. The effect of smoking on the need for immunosuppressive drugs was related to amount smoked and was significant for women but not for men. For female smokers, the 10-year risk of immunosuppressive therapy was $52 \pm 4 \%$ compared with $24 \pm 10 \%$ for nonsmokers $(P<0.0001)$. Cottone et al (50) used multivariate analysis to show that smoking was a risk factor for clinical, surgical and endoscopic recurrence of $\mathrm{CD}$, independent of sex, age at diagnosis, time between onset of symptoms and surgery, extent of disease and extraintestinal manifestations. Wright (51) followed 239 patients to first relapse and found that smoking may adversely affect the clinical course of $C D$.

The pathogenic mechanism, or mechanisms, by which smoking increases the risk of CD have not been established. Suggested mechanisms include thrombogenic effects, effects on intestinal defenses and bloodflow to the intestine, and immunological alterations (44,52-54).

Thus, there is growing evidence that cigarette smoking is a risk factor for $\mathrm{CD}$ in both women and men. Female smokers appear to be particularly at risk of CD. In a number of studies that examine the risk associated with smoking separately in women and men, the excess risk found in female smokers compared with nonsmokers has clearly exceeded the excess risk in male smokers compared with nonsmokers. Smoking also appears to affect the clinical course of $\mathrm{CD}$ adversely in both women and men, but these adverse effects of smoking are more pronounced in women. While further study of the possible interaction of smoking and oral contraceptive use is indicated, women who smoke have an increased risk of $\mathrm{CD}$, irrespective of oral contraceptive use.

\section{ULCERATIVE COLITIS}

As is the case with $\mathrm{CD}$, the pathogenesis of $\mathrm{UC}$ is not well understood. However, the steadily growing evidence that current smoking protects against UC is important because it suggests the possibility of therapeutic intervention. That is, if this protection is due to a constituent of cigarette smoke, such as nicotine, then such a constituent might be administered as part of a treatment regimen. Indeed, a therapeutic trial of transdermal nicotine for UC was recently reported (55). In this randomized, controlled, double-blind study involving 72 patients with active UC, the addition of transdermal nicotine to conventional maintenance therapy was found to diminish symptoms and increase the probability of complete remission.

In a literature review in the mid-1980s, Calkins and Mendeloff (2) noted that data from a number of studies suggest that the risk of UC in current smokers is reduced compared with never smokers. In her subsequent meta-analysis, Calkins (37) commented on the high degree of consistency in the findings from the various reports available at the time. She calculated a pooled odds ratio of 0.41 (95\% CI 0.34 to 0.48 ) for current smokers compared with never smokers. Contrarily, for former smokers compared with never smokers, the pooled odds ratio was 1.64 (95\% CI 1.36 to 1.98 ), which is consistent with the expectation that cessation of a protective behaviour would increase risk. Dose-response relationships were also discernible, in that the degree of protection in current smokers and the degree of risk in former smokers generally increased with increased smoking.

Other reviews $(56,57)$ and reports add further weight to the evidence that current smoking protects against UC. For example, Srivasta et al (58) studied a community in Cardiff, Wales and found that smokers were unrepresented among patients with UC compared with the general population, while never smokers and former smokers were overrepresented. Silverstein et al (59) reported, in a case-control study, an odds ratio of 0.13 (95\% CI 0.05 to 0.38 ) in current smokers and 1.24 (95\% CI 0.52 to 2.95) in former smokers compared with those who had never smoked. Similar findings were reported in two case-control studies in Japan $(60,61)$. In one study, Nakamura and Labarthe (61) found odds ratios of 0.30 (95\% CI 0.18 to 0.50 ) in current smokers and 1.67 (95\% CI 0.97 to 2.88) in former smokers compared with never smokers. Significant dose-response relationships were observed. Risk was lowest among the heaviest current smokers and highest among the heaviest former smokers. Risk was also related to duration of smoking, with the lowest risk in current smokers who had smoked the longest and the highest risk in comparable former smokers. In this study, the risks in women and men were analyzed separately. The reduction in risk in female current smokers was less than that in male current smokers, while the elevation in risk in female former smokers was greater than that in male former smokers. However, English et al (17) found little evidence from a recent meta-analysis that effects were different in females and males (Table 1), although there was considerable heterogeneity among the studies considered.

Sandler et al (62) conducted a case-control study in North Carolina and found that active smokers were less likely to develop UC than never smokers who had not been exposed to environmental tobacco smoke in childhood (odds ratio $0.53,95 \%$ CI 0.24 to 1.14 ). However, never smokers who had been exposed to environmental tobacco smoke in childhood had a reduced risk (odds ratio 0.50, 95\% CI 0.25 to 1.00 ) compared with those who were unexposed. However, Persson et al (40) failed to find any protective association between environmental tobacco smoke exposure in childhood and risk of UC in adulthood, although their findings were consistent with a protective effect of active smoking, an effect that was largely confined to women. They also reported increased risks among former smokers of both sexes, especially among those who had recently quit smoking, a finding reported by others $(38,57,61,63)$. However, Boyko et al (64) and Silverstein et al (59) did not find an association between years of smoking cessation and risk.

Most recently, Merrett et al (65) reported that smokers with UC may be at significantly less risk of pouchitis following ileal pouch-anal anastomosis than nonsmokers and former smokers. They suggested that a controlled trial of nicotine for prevention of pouchitis be conducted. 
Some subgroups of women are thought to be predisposed to UC (2). In particular, a female predominance of UC was found in populations of mainly English or Northern European origin. Tysk and Järnerot (66) examined changes in sex distribution of patients in UC studies reported from 1930 to 1990. In earlier studies, women predominated, whereas in more recent studies men have predominated. No such changes over time were found in studies of UC in pediatric populations. The authors speculated that this change in sex distribution of adult patients was not related to the disease itself, but rather to concurrent changes in smoking habits of men and women, which did not affect children. They hypothesized that, because of their much higher rates of smoking, men were more protected against UC than were women in the early part of this period. However, in recent years, rates of smoking in men and women have become much more similar, due in part to increases in smoking among women from about World War II into the 1960s and to a large decline in smoking among men. The decline in smoking among men would increase their population risk of UC, through both a decrease in protection associated with current smoking and an increased risk associated with former smoking. In women, an increase in smoking would tend to decrease the risk of UC in this population, and because rates of smoking have not declined to the same extent as they have in men, the excess risk associated with former smoking would not operate to the same extent as it would in men.

Thus, it can be concluded that current smoking may protect against UC in both women and men. Evidence from a recent clinical trial that nicotine administered therapeutically to patients with UC leads to symptomatic improvement and even complete remission is of considerable importance.

\section{GALLBLADDER DISEASE}

The authors of several studies suggest that the relationship between smoking and gallstones warrants further study. In a prospective study of symptomatic gallstones in more than 90,000 women enrolled in the Nurses' Health Study in the United States, current smokers were found to have a slightly higher risk than never smokers (67). A relative risk of 1.3 (95\% CI 1.0 to 1.7 ) was calculated by multivariate analysis, taking into account oral contraceptive use, body mass index, weight change, alcohol use and parity. In women who smoked heavily ( 35 or more cigarettes per day), the relative risk was 1.5 (95\% CI 1.20 to 1.89 ) (68). McMichael et al (69) performed a multivariate analysis that took time relationships into account and found that smoking may be a particularly strong risk factor for gallbladder disease in women, but not in men, soon after first exposure. A similar time relationship has been found for oral contraceptive use and gallbladder disease. These authors suggest that, if smoking does increase the risk of gallstones, the risk may be greater in women. They also outlined several smoking-related metabolic changes that might account for a sex difference in the risk of gallbladder disease in relation to smoking. As well, Jorgensen et al (70) performed a multivariate analysis, tak- ing into account body mass index, on a random sample of 70-year-old Danes of both sexes and found that a history of smoking was significantly associated with gallstone disease. However, among younger Danes, the association between smoking and gallstones in multivariate analysis was significant only in men (71).

In the meta-analysis by English et al (17), which pooled data from four studies, the relative risk estimate for any current smoking $(1.24,95 \%$ CI 1.16 to -1.32$)$ was consistent with a weak effect. There was also some evidence of a weak dose-response relationship (Table 1). Also, the confidence interval for the relative risk of former smokers did not include unity (relative risk 1.10, 95\% CI 1.01 to 1.19). There was little evidence that the effects of smoking were different in women and men.

Other studies also provide data suggesting that smoking may be an independent risk factor for gallstones in women (72, 73). More recently, Murray et al (74) examined data from a cohort of 46,000 women followed for up to 19 years during the Royal College of General Practitioners' oral contraception study. Smokers were more likely to develop symptomatic gallbladder disease than nonsmokers (relative risk 1.19, 95\% CI 1.06 to 1.34), and the risk increased with the number of cigarettes smoked per day (test for trend $\chi^{2}=7.58, \mathrm{P}<0.01$ ). This relationship was evident in current and former users of oral contraceptives but was most evident in never users.

The evidence, however, is not entirely consistent. Diehl et al (75) found an effect that was confined to men. Pastides et al (76) found that current smoking protected against gallbladder disease (relative risk $0.5,95 \%$ CI 0.2 to 0.9 ) when alcohol use, other significant dietary factors and personal characteristics were taken into account in a logistic regression analysis. A similar protective effect was demonstrated by Linos et al (77). Still others (78-81) found no association between smoking and gallbladder disease. Because alcohol use is protective against gallstones (17), and alcohol use and smoking are highly correlated, the effects of alcohol and tobacco must be carefully disentangled. Failure to do so may account for some of the inconsistency found in the literature.

\section{CIRRHOSIS OF THE LIVER}

It has been repeatedly documented in large prospective studies (7) that smokers have elevated mortality rates from cirrhosis of the liver compared with nonsmokers. Most recently, Doll et al (9) analyzed data from a 40-year followup of male British doctors and found that current smokers have a fivefold increased risk of cirrhosis compared with non-smokers, with a strong dose-response relationship. As in earlier studies, this study did not control for alcohol use, a strong etiologic factor for cirrhosis of the liver. They noted a strong association of smoking with alcohol use in their subjects and suggested that this association may account for the observed risk of cirrhosis with smoking.

Corrao et al (82) reported, in a recent case-control study of cirrhosis of the liver, evidence of a slight association of cigarette smoking with cirrhosis of the liver. However, the association was not statistically significant, nor was it inde- 
pendent of alcohol consumption. Klatsky and Armstrong (83), however, did find an increased risk of alcoholic cirrhosis among cigarette smokers that was independent of alcohol consumption and several other factors, and was particularly strong in women. These authors considered this finding provocative, in view of that fact that women are believed to be more susceptible to liver toxicity from alcohol and isoniazid (a drug used in the treatment of tuberculosis). They postulated that this susceptibility may extend to other substances, including the effects of cigarette smoke. They also noted the difficulty in disentangling the effects of alcohol consumption and smoking in a disease such as alcoholic cirrhosis because the two behaviours are so strongly associated. The authors of a recent case-control study of men found no association between cigarette smoking and cirrhosis in an analysis using multiple logistic regression (84). Therefore, there is little evidence that smoking is a risk factor for cirrhosis of the liver, independent of alcohol consumption.

differences in duodenal ulcer mortality. Am J Public Health 1986;76:700-2.

17. English DR, Holman CDJ, Milne E, et al. The quantification of drug caused morbidity and mortality in Australia, 1992. Canberra: Commonwealth Department of Human Services and Health, 1995.

18. Vessey MP. Oral contraceptives and pregnancy in relation to peptic ulcer. Contraception 1992;46:349-57.

19. Schöön IM, Mellstrom D, Oden A, et al. Peptic ulcer disease in older age groups in Gothenberg in 1985: The association with smoking. Age Ageing 1991;20:371-6.

20. Endoh K, Leung FW. Effects of smoking and nicotine on the gastric mucosa: A review of clinical and experimental evidence. Gastroenterology 1994;107:864-78.

21. La Vecchia C, Pagano R, Negri E, et al. Smoking and prevalence of disease in the 1983 Italian National Health Survey. Int J Epidemiol 1988;17:50-5.

22. Sontag S, Graham DY, Belsito A, et al. Cimetidine, cigarette smoking, and recurrence of duodenal ulcer. N Engl J Med 1984;311:689-93.

23. Di Mario F, Battaglia G, Leandro G, et al. Risk factors of duodenal ulcer bleeding: the role of smoking and nicotine. Ital J Gastroenterol 1994;26:385-91.

24. Scott AM, Kellow JE, Shuter B, et al. Effects of cigarette smoking on solid and liquid intragastric distribution and gastric emptying. Gastroenterology 1993;104:410-6.

25. Johnson RD, Horowitz M, Maddox AF, et al. Cigarette smoking and rate of gastric emptying: Effect on alcohol absorption. BMJ 1991;302:20-3.

26. McDonnell WG, Owyang C. Effects of smoking on interdigestive gastrointestinal motility. Dig Dis Sci 1995;40:2608-13.

27. Whitfield PF, Hobsley M. Maximal gastric secretion in smokers and non-smokers with duodenal ulcer. Br J Surg 1985;72:955-7.

28. Whitfield PF, Hobsley M. Comparison of maximal gastric secretion in smokers and non-smokers with and without duodenal ulcer. Gut 1987;28:557-60.

29. Quimby GF, Bonnice CA, Burstein SH, et al. Active smoking depressed prostaglandin synthesis in human gastric mucosa. Ann Intern Med 1986;104:616-9.

30. Iwata F, Zhang XY, Lueng FW. Aggravation of gastric mucosal lesions in rat stomach by tobacco cigarette smoke. Dig Dis Sci 1995;40:1118-24.

31. Warren JR. Unidentified curved bacilli on gastric epithelium in active chronic gastritis. Lancet 1983;i:1273.

32. Marshall B. Unidentified curved bacillus on gastric epithelium in active chronic gastritis. Lancet 1983;i:1273-5.

33. Dooley CP, Cohen H. The clinical significance of Campylobacter pylori. Ann Intern Med 1988;108:70-9.

34. Graham DY. Campylobacter pylori and peptic ulcer disease. Gastroenterology 1989;96:615-25.

35. Nomura A, Stemmermann GN, Chyou PH, et al. Helicobacter pylori infection and the risk of duodenal and gastric ulcer. Ann Intern Med 1994;120:977-81.

36. Bateson MC. Cigarette smoking and Helicobacter pylori infection. Postgrad Med 1993;69:41-4.

37. Calkins BM. A meta-analysis of the role of smoking in inflammatory bowel disease. Dig Dis Sci 1989;34:1841-54.

38. Franceschi S, Panza E, La Vecchia C, et al. Nonspecific inflammatory bowel disease and smoking. Am J Epidemiol 1987;125:445-52. 
39. Silverstein MD, Lashner BA, Hanauer SB, et al. Cigarette smoking and Crohn's disease. Am J Gastroenterol 1989;84:31-3.

40. Persson PG, Ahlbom A, Hellers G. Inflammatory bowel disease and tobacco smoke - a case-control study. Gut 1990;31:1377-81.

41. Tragnone A, Hanau C, Bazzocchi G, et al. Epidemiological characteristics of inflammatory bowel disease in Bologna, Italy incidence and risk factors. Digestion 1993;54:183-8.

42. Vessey M, Jewell D, Smith A, et al. Chronic inflammatory bowel disease, cigarette smoking, and use of oral contraceptives: Findings in a large cohort study of women of childbearing age. BMI $1986 ; 292: 1101-3$.

43. Sandler RS, Wurzelmann JI, Lyles CM. Oral contraceptive use and the risk of inflammatory bowel disease. Epidemiol 1992;3:374-87.

44. Wakefield AJ, Sawyer AM, Hudson M, et al. Smoking, the oral contraceptive pill, and Crohn's disease. Dig Dis Sci 1991;36:1147-50.

45. Katschinski B, Fingerle D, Scherbaum B, et al. Oral contraceptive use and cigarette smoking in Crohn's disease. Dig Dis Sci $1993 ; 38: 1596-600$.

46. Duffy LC, Zielezny MA, Marshall JR, et al. Cigarette smoking and risk of clinical relapse in patients with Crohn's disease. Am J Prev Med $1990 ; 6: 161-6$.

47. Sutherland LR, Ramcharan S, Bryant H, et al. Effect of cigarette smoking on recurrence of Crohn's disease. Gastroenterology $1990 ; 98: 1123-8$.

48. Lindberg E, Järnerot G, Huitfeld B. Smoking in Crohn's disease. Effect on localization and clinical course. Gut 1992:33:779-82.

49. Cosnes J, Carbonnel F, Beaugeriel Quintrea Y, et al. Effects of cigarette smoking on the long-term course of Crohn's disease. Gastroenterology 1996;110:424-31.

50. Cottone M, Rosselli M, Orlando A, et al. Smoking habits and recurrence in Crohn's disease. Gastroenterology 1994;106:643-8.

51. Wright JP. Factors influencing first relapse in patients with Crohn's disease. J Clin Gastroenterol 1992;15:12-6.

52. Cope GF, Heatley RV. Cigarette smoking and intestinal defences. Gut 1992;33:721-3.

53. Rhodes J, Thomas GAO. Smoking: Good or bad for inflammatory bowel disease? Gastroenterology 1994;106:807-10.

54. Benoni C. Lifestyle issues in inflammatory bowel disease. Smoking. Can J Gastroenterol 1994;8:422-7.

55. Pullan RD, Rhodes J, Ganesh S, et al. Transdermal nicotine for active ulcerative colitis. N Engl J Med 1994;330:811-5.

56. Cope GF, Heatley RV, Kelleher J, et al. Cigarette smoking and inflammatory bowel disease: A review. Hum Toxicol 1987;6:189-93.

57. Osborne MI, Stansby GP. Cigarette smoking and its relationship to inflammatory bowel disease: A review. J R Soc Med 1992;85:214-6.

58. Srivasta ED, Newcombe RG, Rhodes J, et al. Smoking and ulcerative colitis: A community study. Int J Colorectal Dis $1993 ; 8: 71-4$.

59. Silverstein MD, Lashner BA, Hanawer SB. Cigarette smoking and ulcerative colitis: A case-control study. Mayo Clin Proc $1994 ; 69: 425-9$

60. Kono S, and the Epidemiology Group of the Research Committee of Inflammatory Bowel Disease in Japan. Dietary and other risk factors of ulcerative colitis: a case-control study in Japan. J Clin Gastroenterol $1994 ; 19: 166-71$.

61. Nakamura Y, Labarthe DR. A case-control study of ulcerative colitis with relation to smoking habits and alcohol consumption in Japan. Am J Epidemiol 1994;140:902-11.

62. Sandler RS, Sandler DP, McDonnell CW, et al. Childhood exposure to environmental tobacco smoke and the risk of ulcerative colitis. Am J Epidemiol 1992;135:603-8.

63. Franceschi S, La Vecchia C. Nonspecific inflammatory bowel disease and smoking. Am J Epidemiol 1988;127:697-8.
64. Boyko EJ, Koepsell TD, Perera DR, et al. Risk of ulcerative colitis among former and current cigarette smokers. N Engl J Med $1987 ; 316: 707-10$.

65. Merrett MN, Mortensen N, Kettlewell M, et al. Smoking may prevent pouchitis in patients with restorative proctocolectomy for ulcerative colitis. Gut 1996:38:362-4.

66. Tysk C, Järnerot $\mathrm{G}$. Has smoking changed the epidemiology of ulcerative colitis? Scand J Gastroenterol 1992;27:508-12.

67. Grodstein F, Colditz GA, Hunter DJ, et al. A prospective study of symptomatic gallstones in women: Relation with oral contraceptives and other risk factors. Obstet Gynecol 1994;84:207-14.

68. Stampfer MJ, Maclure KM, Colditz GA, et al. Risk of symptomatic gallstones in women with severe obesity. Am J Clin Nutr $1992 ; 55: 652-8$.

69. McMichael AJ, Baghurst PA, Scragg RKR. A case-control study of smoking and gallbladder disease: Importance of examining time relations. Epidemiology 1992;3:519-22.

70. Jorgensen T, Kay L, Schultz-Larsen K. The epidemiology of gallstones in a 70-vear-old Danish population. Scand I Gastroenterol $1990 ; 25: 335-40$

71. Jorgensen T. Gallstones in a Danish population. Relation to weight, physical activity, smoking, coffee consumption, and diabetes mellitus. Gut 1989;30:528-34.

72. Pettiti DB, Friedman GD, Klatsky AL. Association of a history of gallbladder disease with a reduced concentration of high-density-lipoprotein cholesterol. N Engl J Med 1981;304:1396-8.

73. Layde PM, Vessey MP, Yeates D. Risk factors for gall-bladder disease: a cohort study of young women attending family planning clinics. J Epidemiol Commun Health $1982 ; 36: 274-8$.

74. Murray FE, Logan RFA, Hannaford PC, et al. Cigarette smoking and parity as risk factors for the development of symptomatic gall bladder disease in women: results of the Royal College of General Practitioners' oral contraception study. Gut 1994:35:107-11.

75. Diehl AK, Haffner SM, Hazuda HP, et al. Coronary risk factors and clinical gallbladder disease: an approach to the prevention of gallstones? Am J Public Health 1987;77:841-5.

76. Pastides H, Tzonou A, Trichopoulos D, et al. A case-control study of the relationship between smoking, diet, and gallbladder disease. Arch Intern Med 1990;150:1409-12.

77. Linos AD, Daras V, Linos DA, et al. Dietary and other risk factors in the aetiology of cholelithiasis: a case-control study. HPB Surg $1989 ; 1: 221.7$.

78. Rhodes M, Venables CW. Symptomatic gallstones - a disease of non-smokers? Digestion 1991;49:221-6.

79. Mohr GC, Kritz-Silverstein D, Barrett-Connor E. Plasma lipids and gallbladder disease. Am J Epidemiol 1991;134:78-85.

80. La Vecchia C, Negri E, D’Avanzo B, et al. Risk factors for gallstone disease requiring surgery. Int J Epidemiol $1991 ; 20 \div 209-15$.

81. Basso L, McCollum PT, Darling MRN, et al. A descriptive study of pregnant women with gallstones. Relation to dietary and social habits, education, physical activity, height and weight. Eur J Epidemiol $1992 ; 8: 629-33$.

82. Corrao G, Lepore AR, Valenti M, et al. The effect of drinking coffee and smoking cigarettes on the risk of cirrhosis associated with alcohol comsumption: a case-contorl study. Eur J Epidemiol 1994;10:657-64.

83. Klatsky AL, Armstrong MA. Alcohol, smoking, coffee and cirrhosis. Am I Epidemiol 1992;136:1248-57.

84. Bourliere M, Barthet M, Berthezene P, et al. Is tobacco a risk factor for chronic pancreatitis and alcoholic cirrhosis? Gut 1991;32:1392-5. 


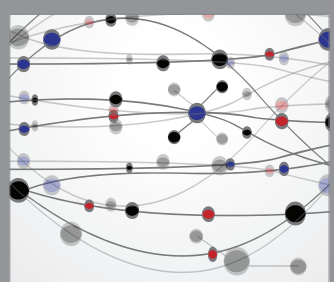

The Scientific World Journal
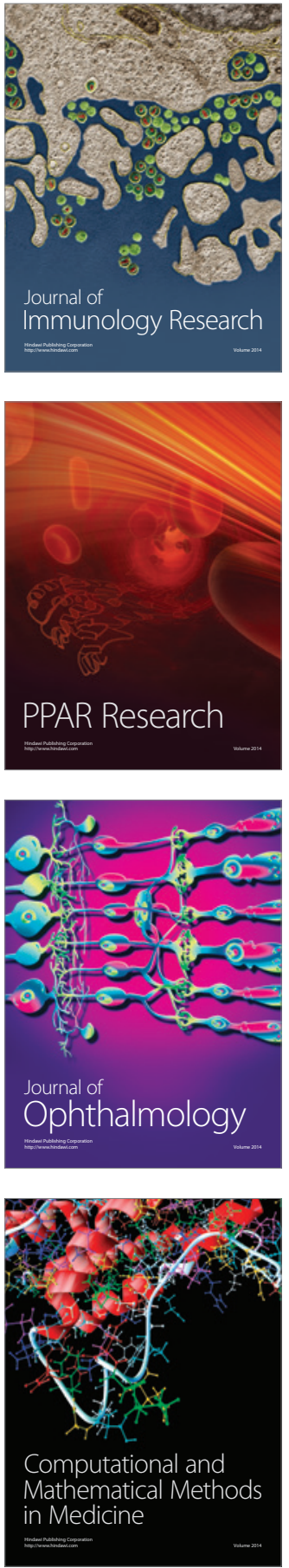

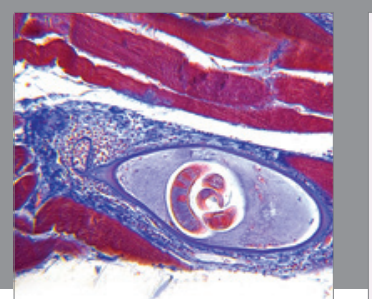

Gastroenterology Research and Practice

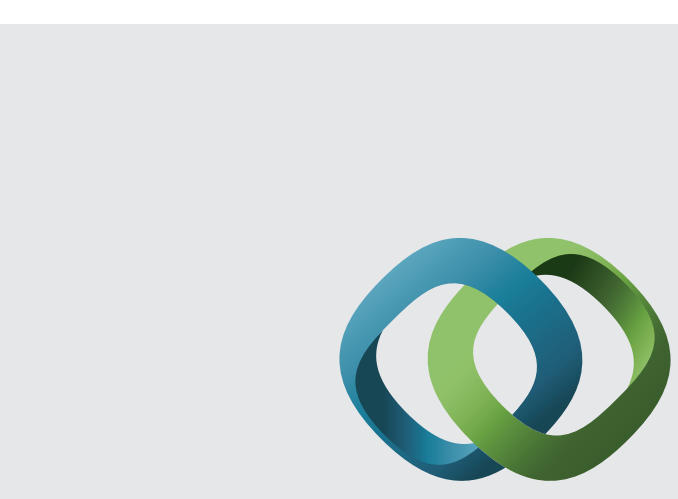

\section{Hindawi}

Submit your manuscripts at

http://www.hindawi.com
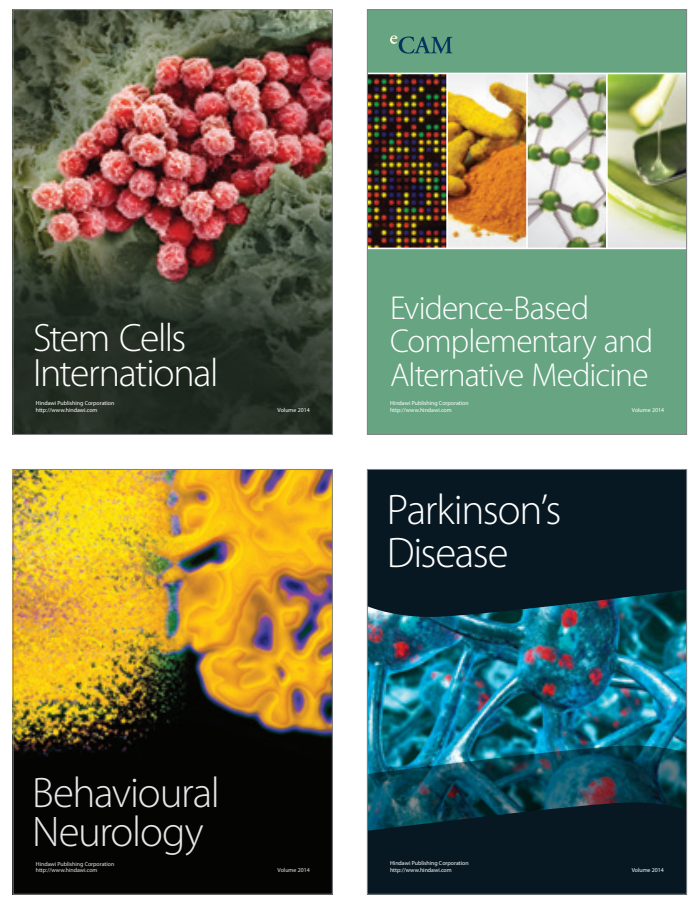
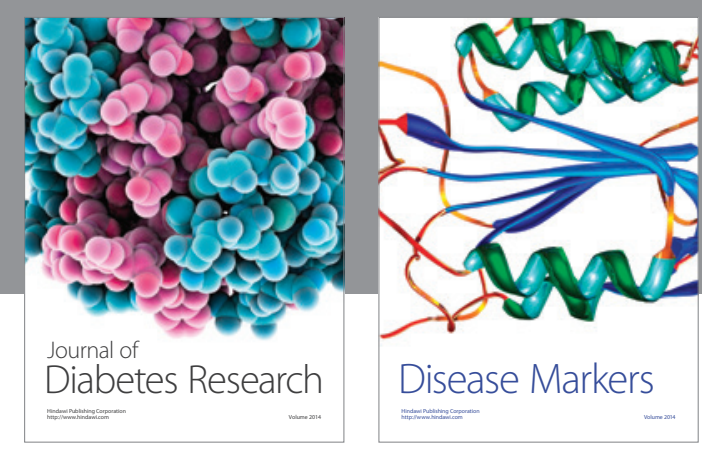

Disease Markers
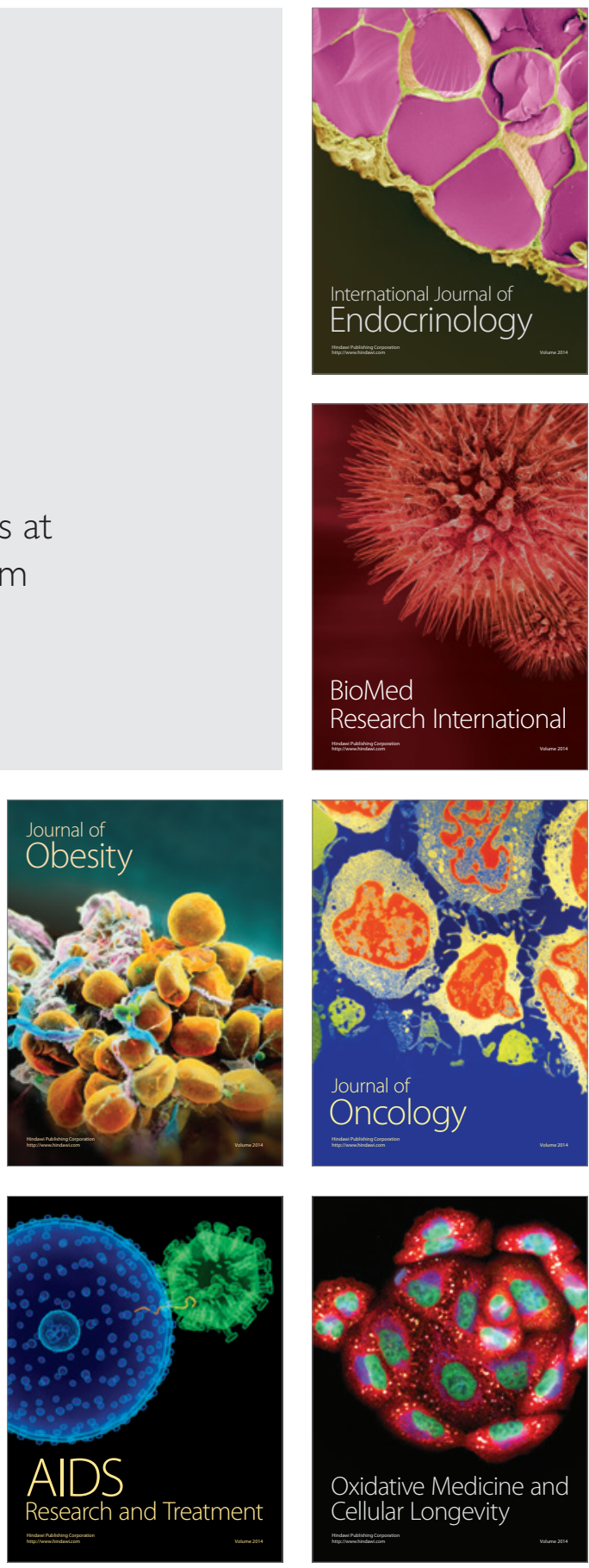